\title{
Economia do Desenvolvimento: das abordagens tradicionais aos novos conceitos de desenvolvimento
}

\author{
Sandrina Berthault Moreira ${ }^{1}$ \\ Nuno Crespo ${ }^{2}$
}

Resumo: A Economia do Desenvolvimento centra a sua análise nos problemas próprios de uma vasta periferia de países menos desenvolvidos. Neste artigo procurámos produzir um survey conciso das principais abordagens que formam o corpo teórico dessa disciplina quanto aos problemas do desenvolvimento, sistematizando-as em quatro vertentes centrais: (i) teorias da modernização; (ii) teorias da dependência; (iii) teoria do sistema-mundo; (iv) contra-revolução neoclássica. Adicionalmente, debatemos os novos conceitos de desenvolvimento que têm emergido nas últimas décadas e que têm permitido alargar a amplitude associada ao conceito de desenvolvimento econômico, enquadrando-os nas agregações conceptuais de desenvolvimento sustentável, local e humano.

Palavras-chave: desenvolvimento econômico; teoria do desenvolvimento.

JEL: O10; O11.

\footnotetext{
${ }^{1}$ Departamento de Economia do Instituto Politécnico de Setúbal (IPS), Portugal. E-mail: sandrina.moreira@esce.ips.pt

2 Departamento de Economia do Instituto Universitário de Lisboa (IUL), Portugal. E-mail: nuno.crespo@iscte.pt
} 


\title{
Development Economics: from the traditional approaches to the new concepts
}

\begin{abstract}
Development economics centers its analysis on the specific problems of a vast periphery of less developed countries. We survey the central elements that characterize four important theoretical bodies in Development Economics, namely: (i) modernization theories; (ii) dependency theories; (iii) world-system theory; (iv) neoclassical counter-revolution. After that, we analyze some of the new concepts of development - human, local and sustainable development emphasizing their contribution to a more adequate understanding of the complex and multidimensional phenomenon of development.
\end{abstract}

Key-words: development economics; sustainable, human and local development.

JEL: O10; O11.

\section{Introducão}

A relevância e a especificidade dos problemas do desenvolvimento levaram ao surgimento de um domínio específico no seio da economia - a Economia do Desenvolvimento. Este emerge, no período posterior à Segunda Guerra Mundial, num contexto internacional marcado pelo advento dos EUA como potência mundial, pela difusão do modelo socialista de origem soviética alémfronteiras e pela desintegração dos impérios coloniais europeus em África, Ásia e América Latina.

A Economia do Desenvolvimento centra a sua análise nos problemas próprios de uma vasta periferia de países menos desenvolvidos da economia mundial, outrora apelidada de "Terceiro Mundo". O seu objetivo último consiste em encontrar respostas para a seguinte questão: «how can low-income economies in the world today be set on the track of sustained economic development for the immediate goal of reducing poverty and the long-run goal of catching up to the wealth of developed economies?» (Hayami e Godo, 2005: 2).

Ao longo das últimas décadas têm sido apresentadas diferentes respostas a esta questão fundamental. No quadro específico da literatura da Economia do Desenvolvimento, a principal argumentação sobre o desenvolvimento pode ser agrupada em quatro corpos teóricos centrais: (i) as teorias da modernização; (ii) as teorias da dependência; (iii) a teoria do sistema-mundo; (iv) a contrarrevolução neoclássica.

Todavia, a "velha" noção de desenvolvimento económico que tem como principal meta diminuir as disparidades de rendimento per capita entre as nações parece limitada para dar conta da amplitude desses problemas (Bonente 
e Filho, 2008). Em resumo, não surpreende que a noção de desenvolvimento se tenha vindo a ampliar mediante a incorporação de novas componentes, sendo apensados inúmeros adjetivos ao substantivo "desenvolvimento".

As novas abordagens do desenvolvimento - sendo a abordagem do desenvolvimento humano e do desenvolvimento sustentável as mais recorrentes - contribuem para a pesquisa de um conceito de desenvolvimento mais humanista, orientado para a natureza humana e o direito de todos a uma vida digna, saudável, esclarecida e justa. Em geral, procuram situá-lo no seio das comunidades, sublinhar a importância da participação das pessoas nas decisões que afetam suas vidas, dar prioridade à satisfação das necessidades básicas e alertar para os perigos do uso descontrolado dos recursos naturais e da rutura com os principais equilíbrios ambientais (Reis, 2005).

Tanto os diversos contributos enquadráveis nas diferentes vertentes da Economia do Desenvolvimento como os vários conceitos alternativos de desenvolvimento que têm emergido fornecem uma riqueza teórica e conceptual que, na sua globalidade, permitem uma leitura mais adequada do complexo e multidimensional fenómeno do desenvolvimento.

O objetivo central deste artigo é produzir um survey conciso deste vasto leque de contributos teóricos de forma a permitir uma visão integrada desses contributos frequentemente abordados de modo separado. Assim, passamos em revista um conjunto diverso de abordagens teóricas sobre a natureza e as causas do atraso no crescimento e desenvolvimento, refletindo, em jeito de conclusão, sobre as perspetivas que emanam das escolas dominantes em relação ao processo de convergência real.

O artigo está estruturado da seguinte forma. Na seção 2, são sintetizadas as ideias centrais subjacentes aos contributos teóricos mais relevantes da Economia do Desenvolvimento. Na seção 3, são apresentadas três vertentes de análise em torno das quais se centram os novos conceitos de desenvolvimento que foram surgindo nas últimas décadas, nomeadamente de desenvolvimento sustentável, local e humano. A seção 4 apresenta algumas observações conclusivas. 


\section{Principais abordagens da economia do desenvolvimento}

\subsection{Teorias da modernização}

Desde o contributo seminal de Rosenstein-Rodan (1943), o pensamento sobre os "problemas e vícios do subdesenvolvimento" centra-se no conceito de desenvolvimento enquanto processo de modernização, i.e. uma mudança estrutural em que os países menos desenvolvidos se tornam progressivamente semelhantes aos países desenvolvidos (Martinussen, 1997). Historicamente, a acumulação de capital e a industrialização haviam sido os motores do crescimento sustentado dos países desenvolvidos, pelo que haveria também de ser este o caminho a seguir pelos países em desenvolvimento. Com essa base comum, os teóricos da modernização propõem visões alternativas sobre as causas do subdesenvolvimento (essencialmente de natureza interna) e as formas para a sua superação.

Entre as principais teorias da modernização, destacam-se as seguintes: (i) o "grande impulso" de Rosenstein-Rodan (1943); (ii) o "crescimento equilibrado" de Nurkse $(1952,1953)$ - em sequência do mecanismo que ficou conhecido como "círculo vicioso da pobreza"; (iii) a estratégia de "crescimento desequilibrado" de Hirschman (1958); (iv) a tese da "causalidade circular e cumulativa" de Myrdal (1957); (v) os "polos de crescimento" de Perroux (1955); (vi) o "modelo dos dois setores com oferta ilimitada de força de trabalho" de Lewis (1954, 1955); (vii) a "descolagem" da teoria das etapas de crescimento de Rostow (1956, 1960).

\section{(i) Crescimento equilibrado vs desequilibrado}

Rosenstein-Rodan (1943) identifica os fatores centrais que impedem um investimento industrial por parte de empresas privadas nas regiões subdesenvolvidas. Em sequência, o autor sugere uma estratégia de desenvolvimento de "grande impulso" (big push), envolvendo ativamente o Estado na educação da força de trabalho e no planeamento e organização de programas de investimento de grande dimensão. ${ }^{1}$

A proposição "um país é pobre porque é pobre" resume o "círculo vicioso da pobreza". O baixo rendimento per capita que caracteriza as economias subdesenvolvidas é o ponto de partida de Nurkse (1952,1953) para a identificação dos dois tipos de bloqueio à formação de capital - o baixo poder de compra e a fraca capacidade de poupança - e cujo resultado final

1 Krugman (1994) define a chamada "teoria do grande desenvolvimento" (high development theory) como "the view that development is a virtuous circle driven by external economies - that is, that modernization breeds modernization» (Krugman, 1994: 41) e, no entendimento do autor, o big push de Rosenstein-Rodan resume o essencial desta teoria. 
é a reprodução de pobreza. ${ }^{2}$ A superação destes constrangimentos requer, simultaneamente, a indução de investimento e a mobilização de recursos para financiamento. Assim, tal como Rosenstein-Rodan, Nurkse advoga uma estratégia de "crescimento equilibrado" (balanced growth), i.e. "a synchronised and simultaneous application of capital throughout industry in order to bring about a generalised expansion of the market» (Oman e Wignaraja, 1991: 18).

Por sua vez, para Hirschman (1958), a escassez de conhecimentos e competências organizacionais e de gestão é o obstáculo primordial ao desenvolvimento nas economias subdesenvolvidas. A aplicação de uma estratégia de crescimento equilibrado, ao exigir uma quantidade considerável deste tipo de skills, leva o autor a argumentar que «if a country were ready to apply the doctrine of balanced growth, then it would not be underdeveloped in the first place» (Hirschman, 1958: 54). Alternativamente, Hirschman propõe a criação deliberada de desequilíbrios, mediante o envolvimento ativo do Estado na indução de investimentos em setores chave caracterizados por "many links backwards and forwards in the economy".

Myrdal (1957) salienta a existência de forças que induzem um processo de causalidade circular e cumulativa que acentua o desequilíbrio, fazendo com que as regiões inicialmente menos desenvolvidas fiquem ainda mais afastadas face às mais avançadas. Ao contrário do designado "movimento circular" dos fatores produtivos, o autor entende que tanto o trabalho como o capital são atraídos para as regiões mais dinâmicas, fruto da superior remuneração de que aí beneficiam. A existência de ganhos de escala e de aglomeração permite, por sua vez, o aprofundamento do processo cumulativo de desequilíbrio. Apesar de também existirem efeitos positivos das regiões mais favorecidas para as menos desenvolvidas - spread effects - (por exemplo, um volume acrescido de procura ou a difusão de tecnologia), para Myrdal (1957) predominam os efeitos negativos - backwash effects - levando ao aprofundamento do diferencial de desenvolvimento. Resulta desse facto a necessidade de uma intervenção pública tendente a evitar que estes processos cumulativos de desequilíbrio económico e social se tornem demasiado significativos.

De igual modo, Perroux (1955) sustenta a concentração do crescimento em certos setores situados em enclaves geográficos, através da noção de "polos de crescimento" (growth poles) suscetíveis de induzir o desenvolvimento. Esses polos - "propellant industries, geographically concentrated poles of industry and activity» (Perroux, 1955: 288) - são largamente responsáveis por induzirem o crescimento nas restantes indústrias e mesmo na economia como um todo, através de vários tipos de efeitos de encadeamento e economias externas.

2 De acordo com Nurkse, uma causa adicional para a fraca capacidade de poupança que caracteriza estes países é o chamado "efeito Duesenberry", i.e. a tendência de imitação dos padrões de consumo prevalecentes nos países desenvolvidos por parte dos consumidores dos países em desenvolvimento. 
(ii) Abordagens de A. Lewis e W. Rostow

A abordagem funcionalista de Artur Lewis e a perspetiva evolucionista de Walt Rostow dominaram a literatura da Economia do Desenvolvimento das décadas de 1950 e princípios de $1960 .^{3}$

Lewis (1954) desenvolve um modelo de economia dual dinâmica, composta por um setor tradicional ou de subsistência e por um setor moderno ou capitalista, a partir do qual o desenvolvimento é encarado como um processo de expansão do setor moderno e de contração do setor tradicional até que a economia deixe de ser dualista. O ponto de partida do autor é a existência de um excedente de força de trabalho a um salário de subsistência, que pode ser absorvido pelo setor moderno com a prática de um salário ligeiramente acima daquele para induzir a migração rural-urbana. Uma vez que este salário permanece fixo enquanto a oferta de trabalho for perfeitamente elástica (ilimitada), o lucro do capitalista é sucessivamente reinvestido, proporcionando a expansão do setor moderno e a contração do setor tradicional. Em resultado deste processo, os lucros aumentam em proporção do rendimento nacional, superando-se assim o principal constrangimento ao crescimento económico - a escassez de acumulação de capital devida, por sua vez, às baixas taxas de poupança. ${ }^{4}$

Rostow (1956) considera que a "descolagem" (take-off) é a etapa crucial da evolução histórica das sociedades, no sentido em que abre caminho a estádios mais avançados de desenvolvimento caracterizados pela completa modernização da economia e da sociedade. As três principais proposições do autor para a concretização do take-off são: (i) um aumento significativo da taxa de investimento; (ii) o surgimento de "setores de vanguarda" (primary/ leading sectors) que podem funcionar como motores do crescimento económico; (iii) a criação de um enquadramento institucional, social e político que dê suporte ao processo de industrialização e seja capaz de sustentar o crescimento económico.

As etapas que antecedem o take-off proposto pelo autor - a sociedade tradicional e a sociedade de transição - são concebidas como etapas inferiores de desenvolvimento, enquanto as duas etapas seguintes - o caminho para a maturidade e a era do consumo de massas - consagram a passagem para os estádios mais avançados de desenvolvimento, onde as economias desenvolvidas estariam localizadas (Fortunato, 2000).

No essencial, a teoria das etapas de crescimento de Rostow (1960) traduz que os países em desenvolvimento seguiriam o mesmo padrão de desenvolvimento dos países desenvolvidos. No entanto, "his thesis that all countries pass

3 O processo de modernização remete para princípios evolucionistas e funcionalistas que estão na base de toda a escola (So, 1990). A perspetiva funcionalista privilegia a visão da sociedade como um sistema de instituições interdependentes cujas mudanças são de molde a assegurar a existência de equilíbrio homeostático. Segundo a perspetiva evolucionista, a mudança social é unidirecional, progressista e gradual.

4 Entre as principais extensões do modelo de Lewis, contam-se os modelos de Ranis e Fei (1961) e de Harris e Todaro (1970). 
through the same sequence of five economic stages, from stagnant subsistence economy to the age of high mass consumption, with each transitional stage being of similar duration in all countries, was soon discredited by appeal to historical evidence» (Hunt, 1989: 96).

Nas suas contribuições centrais para a escola da modernização, Rostow e Lewis apresentam uma visão comum sobre determinados pontos-chave, dos quais se destacam os seguintes: (i) a medida central do crescimento económico é o aumento do rendimento per capita; (ii) o desenvolvimento económico é concebido como um processo de modernização; (iii) a condição de partida para este processo de transformação é a existência de uma oferta de trabalho abundante no setor tradicional; (iv) a taxa de poupança é o determinante central da taxa de investimento e este, por sua vez, da taxa de crescimento económico; (v) a classe capitalista (Lewis) ou empreendedora (Rostow) constitui uma força motriz do crescimento económico, em particular, para o arranque desse processo (Hunt, 1989).

Em suma, a literatura do desenvolvimento anglo-saxónico do segundo período pós-guerra considera que o crescimento económico é um processo condicionado pelas possibilidades de superação de estrangulamentos internos que se relacionam com a acumulação de capital na indústria ou no setor moderno da economia. A ênfase destes autores está na especificação do potencial caminho a seguir para o progresso económico das regiões largamente pré-industriais e sua possível aproximação aos níveis de rendimento per capita das regiões industrializadas. Na eventualidade de um país não conseguir criar as condições necessárias para entrar num círculo virtuoso do desenvolvimento, o país mantém-se subdesenvolvido - "stuck in a low-level trap" - e em estado de divergência real.

\subsection{Teorias da dependência}

Uma série de interpretações mais radicais emerge desde meados da década de 1960, argumentando que a dominação económica exercida pelos países mais avançados sobre os chamados "países atrasados" (backward countries) é um fator impeditivo do desenvolvimento muito mais importante do que as condições internas destes países. O enquadramento da análise da dependência e suas implicações para o desenvolvimento/subdesenvolvimento provém de teóricos de inspiração estruturalista e neomarxista. Ainda que ambas as perspetivas de análise apresentem semelhanças quanto à posição das economias subdesenvolvidas no sistema económico internacional, elas diferem em aspetos importantes como a natureza do processo de desenvolvimento, as suas causas dominantes e o caminho a seguir para a superação das mesmas. 


\section{(i) Estruturalismo}

O pensamento estruturalista sobre o desenvolvimento está intimamente relacionado a autores latino-americanos da Comissão Económica para a América Latina (CEPAL), emergindo com os trabalhos de economistas como Raul Prebisch, Celso Furtado e Osvaldo Sunkel, embora estendendo-se além da América Latina com os contributos de economistas como Paul Singer e Dudley Seers. O estruturalismo refuta as teses da ortodoxia liberal na defesa do interesse, para todos os países, da liberdade de trocas e da especialização internacional assente no princípio das vantagens comparativas. O pessimismo em relação às relações internacionais encontra o seu fundamento central na tendência para o declínio dos termos de troca para os produtos primários, tese desenvolvida por Prebisch (1949) e Singer (1950), num quadro em que o mundo está dividido entre centro e periferia. Não sendo possível basear a industrialização dos países periféricos nos mercados internacionais - e sendo a iniciação deste processo cada vez mais difícil com o passar do tempo e a subsequente deterioração acrescida dos termos de troca - a substituição de importações é advogada como a principal estratégia para o desenvolvimento destes países.

Os pontos essenciais do pensamento estruturalista podem ser resumidos da seguinte forma: (i) o objeto do desenvolvimento é a transformação estrutural das economias subdesenvolvidas, sendo as duas principais características do desenvolvimento económico a expansão da atividade económica através da utilização das tecnologias produtivas mais avançadas e a mudança da composição sectorial; (ii) as estruturas existentes nas economias subdesenvolvidas são, historicamente, determinadas pelo modo como estas se inseriram na economia internacional e, em consequência, são estruturas económicas dualistas em que o setor moderno está orientado para a produção e exportação de produtos primários em troca da importação de produtos manufaturados; (iii) nestas condições, as economias subdesenvolvidas são incapazes de gerar a sua própria dinâmica de crescimento ou alcançar o desenvolvimento económico, sendo necessário, portanto, sair desta dependência de procura externa de exportações primárias como motor do crescimento, desenvolvendo o seu próprio setor industrial diversificado; (iv) o Estado assume um papel central neste processo de transformação estrutural, mediante a adoção de uma estratégia de industrialização por substituição de importações (ISI) (Hunt, 1989).

Interpretações da dependência do subdesenvolvimento surgem, de forma explícita, em trabalhos de estruturalistas como Furtado (1973) e Sunkel (1973). Nesse âmbito, as leituras quanto às perspetivas futuras dos países subdesenvolvidos são mais moderadas do que o otimismo partilhado da perspetiva da modernização, i.e. «[they] will eventually catch up with the Western countries» (So, 1990: 108). Contudo, as leituras mais pessimistas quanto ao futuro dos países do Terceiro Mundo advêm de autores neomarxistas. 


\section{(ii) Perspetiva neomarxista}

As abordagens do "desenvolvimento do subdesenvolvimento" de Frank (1967), da "estrutura da dependência" de Dos Santos (1970) e da "transição para o capitalismo periférico" de Amin (1976) constituem as teorias centrais da escola da dependência de inspiração neomarxista.

A expressão “desenvolvimento do subdesenvolvimento" define a tese central de Frank (1967), expressando que o subdesenvolvimento não é uma condição natural mas antes um artefacto criado pela experiência de dominação colonial dos países do Terceiro Mundo. O autor apresenta uma estrutura piramidal com metrópoles e satélites, através da qual se extrai o excedente económico (sob a forma de matérias-primas, minerais, lucros, etc.) das aldeias da periferia para as capitais locais, as capitais regionais, as capitais nacionais e, finalmente, as cidades do centro. Frank (1967) argumenta que este mecanismo de transferência de excedente económico da periferia para o centro produziu subdesenvolvimento nos primeiros e desenvolvimento nos segundos, sugerindo que a melhor estratégia de desenvolvimento dos países do Terceiro Mundo consiste em "de-linking from the world market".

Dos Santos (1970) define dependência como "a situation in which the economy of certain countries is conditioned by the development and expansion of another economy to which the former is subjected» (Dos Santos, 1970: 271). As relações de interdependência assumem um caráter de desigualdade, na medida em que o desenvolvimento dos países dominantes surge em detrimento dos países dependentes. Dos Santos identifica três formas históricas de dependência - "dependência colonial”, "dependência financeira-industrial" e "dependência tecnológica-industrial" (ou "nova dependência"). O autor dedica especial atenção a esta última, que emerge no segundo período pós-guerra e está associada ao início do processo de desenvolvimento industrial de vários países subdesenvolvidos. Para Dos Santos, estas várias relações de dependência "place fundamental limits on the scope for development", especialmente a nova dependência, dado que, no âmbito desta, o desenvolvimento industrial depende do setor exportador, é influenciado pelas flutuações na balança de pagamentos (que conduzem a défice) e é fortemente condicionado pelo monopólio tecnológico exercido pelos países do centro.

A análise da "transição para o capitalismo periférico" de Amin (1976) tem por base dois tipos de economias, classificadas sobretudo em termos da sua estrutura produtiva - uma "economia autocêntrica" de centro e uma "economia dependente" de periferia. O autor fundamenta que a estrutura de produção que caracteriza os países periféricos - designadamente, o predomínio de um setor exportador "sobre desenvolvido" e a quase inexistência (ou mesmo ausência) de uma indústria de bens de capital e de um setor de bens manufaturados para o consumo de massas - é o resultado da dominação dos países do 
centro. Assim sendo, "peripheral capitalism is unable to attain autocentric and autodynamic economic growth without challenging the domination of foreign monopolies and central capitalism» (So, 1990: 103).

Apesar da diversidade de abordagens que caracterizaram a escola da dependência, é possível identificar um conjunto de ideias fundamentais: (i) a dependência é uma condição imposta do exterior, i.e. os principais obstáculos ao desenvolvimento destes países não são de natureza interna, centrando-se antes na herança histórica do colonialismo e na perpetuação de uma desigual divisão internacional do trabalho; (ii) a dependência é sobretudo uma condição económica, i.e. um resultado da transferência de excedente económico dos países do Terceiro Mundo para os países capitalistas; (iii) o subdesenvolvimento da periferia e o desenvolvimento do centro são as duas faces do mesmo processo de acumulação de capital, conduzindo à polarização regional da economia global; (iv) o desenvolvimento genuíno da periferia é um cenário improvável dado o fluxo contínuo de excedente para o centro (So, 1990).

(iii) Nova dependência de F. H. Cardoso e seus seguidores

Em contraste com as teorias clássicas da dependência, uma nova categoria de contribuições para a análise da dependência emerge durante a década de 1970, associada aos trabalhos de Fernando Henrique Cardoso, Vitória dos Santos, Conceição Tavares, Guilhermmo O’Donnell e Peter Evans. A visão central dos novos estudos da dependência, traduzida na expressão "desenvolvimento na dependência”, combina duas noções até então consideradas inconciliáveis dependência e desenvolvimento.

Cardoso e Faletto (1979), por exemplo, sustentam que o tipo de desenvolvimento expectável nos países do Terceiro Mundo, mesmo nos mais bem-sucedidos, não corresponde ao padrão de desenvolvimento dos países capitalistas mas ao chamado desenvolvimento na dependência. Como afirma Cardoso (1973), em resultado do crescimento das empresas multinacionais, da imersão de capital industrial nas economias periféricas e de uma nova divisão internacional do trabalho, em certa extensão, os interesses das empresas externas tornamse compatíveis com a prosperidade interna dos países dependentes e, neste sentido, ajudam a promover o desenvolvimento. No entanto, este desenvolvimento dependente resulta numa estrutura produtiva distorcida e desequilibrada, i.e. carece de "tecnologia autónoma", é compelido a utilizar tecnologia importada (suportando as consequências da absorção de uma tecnologia intensiva em capital (labour-saving) e carece de um setor de bens de capital desenvolvido.

Os teóricos da nova dependência conceptualizam que a dependência é um processo historicamente específico, interno e sociopolítico que pode conduzir 
ao desenvolvimento dinâmico. Assim, situando-se num plano mais concreto de apreciação da dependência, os novos estudos da dependência procuram a explicação do subdesenvolvimento na análise das dinâmicas internas de natureza sociopolítica que explicam a dependência, especialmente a luta de classes, os conflitos de grupos e os movimentos políticos, e não tanto nas relações externas e na troca desigual. Por outro lado, em contraste com a previsão de uma tendência unidirecional de subdesenvolvimento nos países da periferia, Cardoso e seus seguidores consideram a possibilidade de desenvolvimento associado à dependência, embora prudentes quanto à sua generalização.

\subsection{Teoria do sistema-mundo de I. Wallerstein}

Durante a década de 1970, um grupo de investigadores liderado por Immanuel Wallerstein dirigem uma visão crítica às teses tanto da modernização como da dependência, embora mantendo uma herança teórica a esta última escola. ${ }^{5}$ A demarcação com as abordagens teóricas anteriores reside na proposta de uma visão sistémica do desenvolvimento que atenda à dinâmica histórica da unidade de análise privilegiada, o sistema-mundo. De facto, não só é defendida a ideia de que o desenvolvimento de um país só pode ser avaliado quando perspetivado no contexto da globalidade do sistema-mundo, como também se entende a história, o desenvolvimento e o subdesenvolvimento a partir de uma conceção dinâmica, caracterizada por ciclos rítmicos e tendências seculares.

Wallerstein $(1974,1979,1980)$ concebeu o sistema-mundo como sendo composto por três camadas - o centro, a periferia e a semiperiferia - em que esta última se situa entre o centro e a periferia e exibe características de ambos. A existência de um modelo trimodal de distribuição dos níveis de desenvolvimento mundial e a base histórica da análise permite-lhe, ainda, admitir a possibilidade de as periferias ascenderem a semiperiferias e estas a posições centrais e vice-versa. De acordo com Wallerstein, «success in moving from periphery to semiperiphery depends on whether the country can adopt one of the following strategies of development: seizing the chance, promotion by invitation, or self-reliance» (So, 1990: 182), enquanto, segundo o mesmo autor, "the key to peripheral breakthrough is that a country must have a market available that is large enough to justify an advanced technology, and for which it must produce at a lower cost than the existing producers» (So, 1990: 184).

Em contraste com a escola da dependência, Wallerstein e seus seguidores recusam o princípio da bipolaridade entre o centro e a periferia, além do determinismo das relações de exploração entre estes dois polos,

5 Graaff e Venter (2001) consideram a teoria do sistema-mundo uma versão mais sofisticada da perspetiva da dependência. 
nomeadamente que a periferia está destinada ao subdesenvolvimento ou ao desenvolvimento dependente. Por outras palavras, «whereas dependency theory offered only one solution out of the prevailing power relations, namely moving out, world-system theory offered one more option, namely moving up or down the hierarchy within the prevailing world system» (BooysenWolthers, 2007: 7).

Em síntese, no quadro da teoria do sistema-mundo, o conceito de semiperiferia rompe com as leituras otimista e pessimista das abordagens teóricas anteriores - teorias da modernização e teorias da dependência, respetivamente - ao abrir a possibilidade de mobilidade vertical das economias. O resultado depende das dinâmicas de acumulação de capital a nível mundial e das contingências e posicionamentos históricos dos diferentes países.

\subsection{Contrarrevolução neoclássica}

A crítica à ortodoxia do desenvolvimento prevalecente entre finais da década de 1950 e princípios de 1960 - estruturalismo latino-americano e modernização - surge não apenas no seio da tradição neomarxista mas também associada à tradição da economia neoclássica. Bauer e Yamey (1957) é um dos trabalhos pioneiros na aplicação da perspetiva neoclássica - em particular, a filosofia do laissez-faire e o princípio das vantagens comparativas - às causas do (e aos obstáculos para o) desenvolvimento económico dos países do Terceiro Mundo.

O ressurgimento do pensamento neoclássico centra-se na análise da relação Estado-mercado no processo de desenvolvimento económico e esteve associado à crítica ao ativismo estatal enfatizado na literatura da Economia do Desenvolvimento desde a sua emergência no segundo pós-guerra. Nessa medida, acaba por constituir-se como uma contrarrevolução neoclássica nos domínios da política e da teoria económica. ${ }^{6}$ Enquanto os teóricos da escola da dependência consideravam o subdesenvolvimento como um fenómeno induzido de forma externa, os autores neoclássicos encaram-no como um problema com causas internas, nomeadamente uma excessiva intervenção governamental e "más" políticas económicas.

6 A expressão "contrarrevolução neoclássica” foi popularizada para caracterizar a penetração neoclássica no domínio da Economia do Desenvolvimento e, em particular, para exprimir a mudança radical que a nova atitude representou face ao pensamento económico então prevalecente neste domínio. 
(i) $1^{\text {a }}$ vaga - abordagem do "mercado livre"

A primeira das duas "vagas de ataque neoclássico" (Shapiro e Taylor, 1990; Taylor, 1993), iniciada na década de 1970, explica os resultados do subdesenvolvimento com base na deficiente afetação de recursos, devida a políticas incorretas de preços e ao excesso de intervenção do Estado pelos governos dos países subdesenvolvidos. De acordo com os autores desta vaga, nesses países, os preços dos produtos agrícolas são artificialmente baixos, as taxas de câmbio sobrevalorizadas, as taxas de juro artificialmente baixas e os níveis dos salários industriais em relação aos agrícolas excessivamente elevados e, como tal, conducentes a um padrão de afetação de recursos distorcido, com a consequente redução em termos de eficiência e bem-estar. Esta argumentação despoletou a estratégia de "formação de preços corretos" (getting prices right), com base no funcionamento livre dos mercados, para a dinamização da eficiência económica e do crescimento económico.

Segundo as análises de McKinnon (1973) e Shaw (1973), as distorções no sistema financeiro compreendem a fixação administrativa das taxas de juro nominais abaixo do seu nível de mercado e a atribuição administrativa do crédito, sendo ambas perniciosas para o investimento e crescimento das economias subdesenvolvidas. De igual modo, teóricos neoclássicos do comércio internacional como Krueger (1974) e Bhagwati (1982) sustentam que a intervenção do Estado nas economias subdesenvolvidas proporciona, respetivamente, atividades de "procura de renda" (rent-seeking) e, em geral, "atividades diretamente improdutivas de procura de lucro".

(ii) $2^{\text {a }}$ vaga - abordagem da "escolha pública"

Na década de 1980, a crítica neoclássica culmina na visão de que o Estado é o problema (e não a solução) do subdesenvolvimento, tida como a contrapartida neoliberal para os países em desenvolvimento da ideologia prescrita pelos países desenvolvidos após a eleição de governos conservadores nos Estados Unidos, na Alemanha e no Reino Unido (Fine, 2003). A minimização do papel do Estado na economia é vista como a melhor ação a empreender na promoção do desenvolvimento (Adelman, 1999).

De acordo com a teoria da escolha pública, o Estado não é uma espécie de "guardião social da benevolência", mas antes constituído por um grande número de atores (políticos, burocratas, tecnocratas, etc.) que atuam somente a partir de uma perspetiva de interesse próprio, usando o seu poder e a autoridade do governo para os seus próprios fins. Krueger (1990) realça que, nos países em desenvolvimento, a dinâmica criada pela intervenção do Estado e pelo protecionismo tende a estar associada ao comportamento de procura de renda, à pressão dos interesses pessoais e de grupos de interesse conflituantes, à burocratização e à corrupção. 
A contrarrevolução neoclássica, nas suas abordagens "mercado livre" (freemarket) e "escolha pública" (public choice), correspondeu, no plano da conceção e definição de políticas de desenvolvimento, a um consenso entre o Fundo Monetário Internacional (FMI), o Banco Mundial e o Tesouro dos Estados Unidos sobre as políticas “certas” para os países em desenvolvimento. O chamado Consenso de Washington materializou-se em Programas de Ajustamento Estrutural (PAE) impostos a países do Terceiro Mundo na década de 1980. O padrão de ação assentava em preceitos que estimulassem a eficiência e o crescimento económico, designadamente «permitting competitive free markets to flourish, privatizing state-owned enterprises, promoting free trade and export expansion, welcoming investors from developed countries, and eliminating the plethora of government regulations and price distortions in fator, product, and financial markets» (Todaro e Smith, 2000: 128). ${ }^{7}$

\section{(iii) Abordagem "amiga do mercado"}

Uma nova variante da contrarrevolução neoclássica emerge no início da década de 1990, a partir da produção literária de economistas do Banco Mundial que empreenderam uma revisão das suas posições teóricas sobre o papel do Estado no processo de desenvolvimento económico. Baseado em análises elaboradas em anteriores Relatórios do Desenvolvimento Mundial (RDM) - em particular os Relatórios de 1991 e 1993 (World Bank, 1991, 1993) - o Banco Mundial, no seu Relatório de 1997, marca um ponto de viragem na conceção do Estado, i.e. "the state is central to economic and social development, not as a direct provider of growth but as a partner, catalyst, and facilitator» (World Bank, 1997: 1).

As reconsiderações acerca do papel do Estado conduzem a uma mudança no pensamento sobre o desenvolvimento, em que a supremacia do mercado - "state intervention in developing countries was cast as a cure that is worse than the disease» (Chang, 2003: 4) - cede lugar a uma perspetiva que considera uma relação de trabalho em parceria, de complementaridade entre o Estado e o mercado - o reconhecimento de que as duas entidades apresentam falhas e limitações. A noção de "Estado mínimo" (minimal state) é substituída pela de "Estado eficaz" (effective state), traduzindo a ideia de que o Estado é um complemento (e não um substituto) dos mercados. Assim, o Estado não só empreende ações que permitam um desempenho mais adequado das funções dos mercados (por exemplo, investindo na infraestrutura institucional de uma economia de mercado, com destaque para as infraestruturas educacionais

7 O Consenso de Washington ficou conotado a um pacote de reformas económicas do tipo "one-size-fits-all" que acompanha os financiamentos das instituições de Bretton Woods - "lenders of last resort" - ou mesmo com a filosofia política do neoliberalismo. Williamson $(1990,2004)$ resume a abordagem do Consenso de Washington nos seguintes pontos: disciplina fiscal; reestruturação das despesas públicas; reforma fiscal; liberalização financeira, comercial e dos fluxos de Investimento Direto Estrangeiro (IDE); taxas de câmbio competitivas; privatização; desregulamentação; proteção dos direitos de propriedade. 
e de saúde), mas também corrige os fracassos do mercado (por exemplo, intervindo em áreas como a coordenação de investimentos e a prevenção dos efeitos ambientais) (Stiglitz, 1998; Todaro e Smith, 2000).

A abordagem neoclássica "amiga do mercado" (market-friendly) difere das anteriores abordagens (free-market e public choice) em dois aspetos essenciais (Estêvão, 1999; Todaro e Smith, 2000). Por um lado, reconhece-se a existência de várias imperfeições nos mercados de produtos e de fatores dos países em desenvolvimento. Por outro lado, sublinha-se que as falhas de mercado são comuns em países em desenvolvimento, podendo acontecer em determinadas situações, designadamente, mercados incompletos, informação imperfeita, externalidades ou economias de escala.

\section{Novos conceitos de desenvolvimento}

A emergência de novos conceitos de desenvolvimento, de forma embrionária durante as décadas de 1950 e 1960 e especialmente a partir da década de 1970, decorre de um leque alargado de fatores. Entre esse conjunto de elementos podem destacar-se os seguintes: (i) as frustações dos países do Terceiro Mundo face à evolução do seu desenvolvimento; (ii) os sinais crescentes de mal-estar social nos países desenvolvidos; (iii) a tomada de consciência dos problemas ambientais provocados pelo desenvolvimento; (iv) as irregularidades do crescimento económico nas décadas seguintes aos "anos dourados"; (v) a multiplicação de crises diversas nos países socialistas (Amaro, 2003).

Estas novas abordagens não pressupõem a negação da importância do crescimento económico para o desenvolvimento. Elas apenas salientam que, embora necessário, ele é insuficiente para assegurar o desenvolvimento. O processo de desenvolvimento deixa de ser definido apenas em função da dimensão económica para passar a ser equacionado com base num conjunto de dimensões interatuantes, das quais se destacam a económica, a social, a política, a cultural e a ambiental (Goulet, 1992).

A nova conceção multidimensional do desenvolvimento resulta do cruzamento de várias visões sobre o conceito e pressupõe uma abordagem interdisciplinar, dada a diversidade de componentes interrelacionadas que o constituem (Brito, 2004).

Inúmeras designações foram sendo apresentadas ao longo do tempo na tentativa de renovação do conceito de desenvolvimento. De igual modo, diferentes propostas de agregação em torno da conceptualização do desenvolvimento foram surgindo na literatura. ${ }^{8}$ Nesta secção, discutimos três vertentes fundamentais em torno das quais a discussão conceptual tem evoluído ao longo das últimas quatro décadas.

8 Veja-se, por exemplo, Clark (2007). 


\subsection{Desenvolvimento sustentável}

No início da década de 1970 emerge o conceito de ecodesenvolvimento, o qual estaria na base do futuro conceito de desenvolvimento sustentável, na sequência de dois acontecimentos importantes com influência decisiva para a afirmação das preocupações com o desenvolvimento e o ambiente a Primeira Conferência das Nações Unidas sobre Ambiente e Desenvolvimento (Conferência de Estocolmo, em 1972) e o estudo encomendado pelo Clube de Roma sobre a compatibilidade das reservas de recursos estratégicos com os ritmos de crescimento (Meadows e Meadows, 1972).

O ecodesenvolvimento - conceito amplamente desenvolvido por Sachs (1980, 1986) - compreende as dimensões económica e ecológica, prevendo a satisfação das necessidades mediante a utilização controlada e racional dos recursos existentes, minimizando os desperdícios e a degradação ambiental. O meio ambiente é encarado com um duplo valor, intrínseco e instrumental, valendo por si mesmo e tendo como função a promoção do crescimento económico. Remetendo para o conceito de sustentabilidade, a preocupação central desta perspetiva consiste em acautelar o desenvolvimento futuro, evitando a destruição no presente de recursos não renováveis. ${ }^{9}$

O "desenvolvimento sustentável” é um conceito que decorre do Relatório de Brundtland, concluído em 1987 e publicado pela Comissão Mundial para o Ambiente e Desenvolvimento (CMAE ou WCED, na sigla inglesa) das Nações Unidas. A definição aí apresentada é a que recolhe maior recetividade internacional: «development that meets the needs of the present generation without compromising the ability of future generations to meet their own needs» (WCED, 1987: 43). Este conceito, ao requerer a disponibilidade de recursos para as gerações futuras, pressupõe solidariedade intergeracional.

A questão da sustentabilidade prende-se igualmente com a gestão dos recursos naturais. Numa primeira fase, a preocupação centrava-se na gestão das reservas de recursos não renováveis (petróleo, minérios e recursos estratégicos em geral). Contudo, o desenvolvimento sustentável passou também a considerar a gestão dos recursos renováveis (por exemplo, os serviços ambientais permitidos pela radiação solar), devido ao problema do ritmo de renovação / qualidade desses recursos. Além disso, o conceito de desenvolvimento sustentável pressupõe uma nova relação com a Natureza, baseada na interdependência sistémica. Tal significa a adoção de uma lógica de contenção, definida por um ritmo sustentável de equilíbrio entre inputs, throughputs e outputs na interação entre a economia e a ecologia (Amaro, 2003).

9 Desenvolvimento alternativo é uma de várias formulações que se seguiram ao conceito de ecodesenvolvimento e que encontraram o seu expoente máximo no conceito de desenvolvimento sustentável. Trata-se de um conceito associado aos "Verdes" alemães (um grupo ecológico que assumiu um importante estatuto político e científico), estando na origem da "política dos $3 \mathrm{R}$ " - reduzir os consumos, reutilizar os produtos e reciclar os materiais. 
O desenvolvimento sustentável visa a satisfação das principais necessidades de todos e a extensão a todos da oportunidade para satisfazer as suas aspirações a uma vida melhor (WCED, 1987). Deste modo, este é um conceito que apresenta dois pilares principais: a utilização dos recursos e a consciência dos seus limites, i.e. o uso sustentável dos recursos naturais na produção e no consumo (Davis, 2009).

O conceito de desenvolvimento sustentável passou a ser amplamente usado, sobretudo a partir da Segunda Conferência das Nações Unidas sobre Ambiente e Desenvolvimento. A Conferência do Rio (também conhecida por Cimeira da Terra ou Eco-92) deu visibilidade internacional ao conceito, sendo, atualmente, um conceito assumido ao nível de várias instâncias e organismos internacionais, bem como dos governos de diversos países, para além das Organizações Não-Governamentais (ONG) que atuam neste domínio. Por seu lado, a Conferência de Joanesburgo (ou Rio+10), realizada em 2002, relativiza a componente ambiental dominante até aqui, realçando uma visão tridimensional da sustentabilidade traduzida nas seguintes três dimensões: viabilidade económica, preservação ambiental e coesão social (Harris, 2001).

\subsection{Desenvolvimento local e metodologia participativa}

O desenvolvimento local parte da herança do desenvolvimento comunitário da década de 1960 - proposto e refletido por autores como Silva $(1962,1963)$ e organizações internacionais como as Nações Unidas - aproveitando os seus três importantes pilares: (i) auscultação das necessidades das populações; (ii) mobilização das capacidades locais como ponto de partida para as respostas; (iii) visão integrada dos problemas e soluções.

Uma multiplicidade de formulações seguiu-se à conceção alternativa do desenvolvimento comunitário e desembocaram no conceito de desenvolvimento local. Entre elas, destacam-se as seguintes: (i) village concept, proposto pela Organização Mundial de Saúde (OMS); (ii) another development (Dag Hammarskjöld Foundation, 1982); (iii) desenvolvimento endógeno ou bottom-up (Stöhr, 1981); (iv) desenvolvimento territorial, de teóricos do paradigma territorialista, com destaque para Stöhr (1990); (v) desenvolvimento participativo.

A definição de "desenvolvimento local" apresentada por autores como Pecqueur (1989), Vachon (1993) ou Houeé (2001) destaca um conjunto de elementos caracterizadores. Em primeiro lugar, o desenvolvimento local é um processo de mudança, de base comunitária, que tem normalmente como ponto de partida a existência de necessidades que atingem o coletivo e às quais se procura responder com recurso prioritário às capacidades locais. Com efeito, o desenvolvimento local fundamenta-se no paradigma territorialista da 
economia regional e das ciências do território, o qual destaca a ideia de que a diversidade de territórios de âmbito infranacional exige uma conceção do desenvolvimento que atenda aos recursos disponíveis, às necessidades locais, que seja diferenciado e multiforme e que parta do potencial endógeno em recursos e capacidades. O novo paradigma do desenvolvimento no território constitui, portanto, uma forma de desenvolvimento a partir de espaços mais restritos, from below.

O desenvolvimento local obedece igualmente a uma lógica participativa, em que é sublinhada a importância da participação das comunidades locais na resolução dos seus problemas e na valorização dos recursos locais. O reforço do poder das pessoas e das comunidades através do aumento das suas capacidades (empowerment) é uma condição para a participação e liderança, aspeto que veio a ser aprofundado por Friedmann (1992). No entanto, também se reconhece que o desenvolvimento local não é autossuficiente, pelo que não se rejeita a necessidade de utilizar recursos exógenos, desde que completem ou potenciem os recursos endógenos.

A visão integrada do contexto em que o problema se manifesta e das respostas que se lhe adequam é outra das componentes-chave do conceito. Tal pressupõe uma lógica de parceria, de trabalho conjunto entre instituições formais e informais, empresas, cidadãos e administração pública, com um empenhamento e participação direta de todos os intervenientes e com impacto tendencial em toda a comunidade.

O desenvolvimento local destaca a importância da participação, embora atribua grande importância aos conceitos de território e comunidade, distinguindo-se, assim, do desenvolvimento participativo, em que as últimas duas dimensões não aparecem como referência. O pilar decisivo do desenvolvimento participativo é o envolvimento das pessoas (de forma individual ou em grupo). Os contributos teóricos mais importantes desta conceção do desenvolvimento são de Friedmann (1992) com o conceito de alternative development e Korten (1992) com a ênfase no "desenvolvimento centrado nas pessoas" (people-centered development), em detrimento do “desenvolvimento centrado nos bens" (goods-centered development).

O "desenvolvimento participativo" não é apenas uma melhoria genuína e duradoura das condições de vida e de existência, mas também uma luta política pelo empowerment dos indivíduos. A participação enquanto conceção de desenvolvimento aproxima-se, assim, da conceção política preconizada por Ghai (1990) ou Friedmann (1992), entre outros, remetendo para a ideia de cidadania e, portanto, democracia ativa e permanente. Segundo Friedmann (1992), empowerment é o reforço das capacidades, competências ou poder como condição para o envolvimento dos cidadãos na definição, execução e avaliação de projetos e/ou programas de desenvolvimento e para o exercício de cidadania, além de ser um processo de efetiva formação e aquisição de poderes por parte da população. 


\subsection{Desenvolvimento humano e compromissos de política social}

A origem do conceito de desenvolvimento humano remonta à década de 1970 e situa-se na reivindicação por parte de responsáveis institucionais na altura, designadamente Mahbub ul Haq no âmbito da Organização Internacional do Trabalho (OIT) e Robert McNamara do Banco Mundial, de que o desenvolvimento tem o seu critério mais importante de aferição na satisfação das "necessidades básicas" (basic needs). Esta reivindicação institucional é acompanhada pelas análises de teóricos como Seers (1979) e Streeten (1981).

O conceito basic needs é definido pela OIT como um conjunto de necessidades fundamentais que têm prioritariamente que ser satisfeitas para toda a população do planeta, i.e. alimentação, vestuário, habitação, educação e saúde (Stöhr, 1990). Partindo do patamar de sobrevivência para o patamar de dignidade mínima, a sobrevivência fisiológica, a educação e a saúde são os pilares das basic needs e o emprego um pilar instrumental (um meio de obter rendimento, fonte de recursos).

A discussão do conceito de desenvolvimento humano a partir das necessidades básicas foi apresentada em 1990 pelo Programa das Nações Unidas para o Desenvolvimento (PNUD ou UNDP, na sigla inglesa), de acordo com o qual o "desenvolvimento humano" é: "a process of enlarging people's choices. In principle, these choices can be infinite and change overtime. But at all levels of development, the three essential ones are people to lead a long and healthy life, to acquire knowledge and to have access to resources needed for a decent standard of living. If these essential choices are not available, many other opportunities remain inaccessible» (UNDP, 1990: 10).

Atualmente, o conceito de desenvolvimento humano é mais complexo e abrangente do que aquele que esteve na sua origem. Além das três componentes consideradas essenciais ao desenvolvimento humano (uma vida longa e saudável, um nível de conhecimentos aceitável e um nível de vida digno), o conceito de desenvolvimento humano passou a integrar outras dimensões como a liberdade, a igualdade de oportunidades, a sustentabilidade e a segurança (UNDP, 1996).

Sen (1999) - colaborador na idealização do conceito de desenvolvimento humano - concebe o desenvolvimento como liberdade, entendida esta no seu sentido amplo, incluindo não só as capacidades elementares como a possibilidade de evitar privações como fome, subnutrição, mortalidade evitável, mortalidade prematura, mas também as liberdades associadas com a educação, a participação política, a proibição da censura, etc. Desenvolvimento é, portanto, segundo o autor, um processo de expansão destas e de outras liberdades fundamentais. 
A equidade (concebida de forma mais lata que a mera distribuição do rendimento) é outra dimensão que tem vindo a assumir uma importância crescente no quadro do desenvolvimento humano. A equidade sublinha o direito de todos (gerações presentes e futuras) a uma igual oportunidade de acesso a uma vida longa e saudável, a um nível de conhecimentos aceitável e a um padrão de vida adequado, i.e. independentemente do género, estrato socioeconómico, origem étnica, escalão etário, opções políticas, ideológicas ou religiosas, ou ainda origem regional.

Por último, a conceção humana do desenvolvimento passou também a incluir a segurança humana, associada não só à subsistência alimentar e satisfação de outras necessidades básicas, mas também à proteção relativamente a desastres naturais ou a coações impostas pela repressão política, pelo crime organizado, etc. (UNDP, 1994).

Em síntese, desenvolvimento humano é um processo de alargamento das escolhas e das oportunidades dos indivíduos, de expansão das liberdades humanas, de valorização das capacidades dos indivíduos, que lhes permitam levar uma vida longa e saudável, adquirir conhecimento, ter acesso aos recursos necessários para um nível de vida digno, enquanto os preservam para as gerações futuras, com igualdade de oportunidades e em segurança.

Segundo esta nova perspetiva do desenvolvimento, o adjetivo "humano" é assumido em três aceções: (i) o homem encontra-se no centro das preocupações; (ii) o bem-estar humano é o fim do desenvolvimento; (iii) o ser humano adquire um papel ativo (participação). Logo, desenvolvimento humano é um processo de desenvolvimento do, para o e pelo ser humano (UNDP, 1998).

A conceção do desenvolvimento humano cruza-se ainda com as questões de "luta contra a pobreza" que assumiu uma dimensão crucial com a Cimeira do Milénio, das Nações Unidas, realizada em 2002, e na sequência da qual se definiram os Objetivos de Desenvolvimento do Milénio (ODM), i.e. «a pact between nations to defeat human poverty» (UNDP, 2003: 31). Pobreza é, em rigor, ausência de desenvolvimento humano, i.e. negação das oportunidades e escolhas mais elementares.

Os compromissos de política social decorrentes da filosofia do desenvolvimento humano foram assumidos na Conferência Mundial sobre o Desenvolvimento Social, organizada pelas Nações Unidas, em 1995, dando origem ao conceito de "desenvolvimento social". Os países-membros comprometeram-se a promover a dimensão social do bem-estar, através da introdução de mínimos sociais como o salário mínimo, o rendimento mínimo, a pensão social mínima, a escolaridade obrigatória, o plano nacional de saúde, entre outros mínimos de bem-estar social. 


\section{Conclusão}

A análise de um fenómeno com a complexidade do desenvolvimento reveste-se de especial dificuldade pela multidimensionalidade que lhe está subjacente. O objetivo central deste artigo foi oferecer uma perspetiva integrada e global dos principais contributos emanados das diferentes perspetivas que compõem o corpo teórico da Economia do Desenvolvimento. Nesse contexto, abordámos: (i) a perspetiva otimista das teorias da modernização, com o enfoque centrado na determinação das condições endógenas de modernização; (ii) a visão mais pessimista das teorias da dependência, realçando a existência de obstáculos externos ao desenvolvimento, ainda que suavizada pela abordagem sociológica e política das lógicas de desenvolvimento dependente das economias em desenvolvimento; (iii) a teoria do sistema-mundo, procurando propiciar uma visão integradora das várias economias num contexto mundial; (iv) a designada contrarrevolução neoclássica, com uma avaliação crítica do papel do Estado, embora posteriormente redefinida no sentido de salientar a complementaridade necessária entre o Estado e o mercado.

Para além deste vasto leque de contributos nucleares, assistiu-se, nas décadas mais recentes, ao reconhecimento das limitações de um conceito de desenvolvimento exclusivamente centrado na dimensão económica. Dessa forma, emergiram vários conceitos que foram alargando o conceito tradicional de desenvolvimento económico. Esses novos conceitos procuravam tornar mais explícita a relevância de outras dimensões do processo de desenvolvimento, nomeadamente a social, humana, local, ambiental, entre outras. Este leque de novas propostas conceptuais acabaria por convergir em torno de três grandes fileiras conceptuais - desenvolvimento sustentável, humano e local.

Embora não excluindo a relevância da emergência de novos conceitos e perspetivas teóricas, cremos que o principal desafio com que a avaliação do desenvolvimento presentemente se confronta, se prende com a necessidade de transpor para o domínio da quantificação empírica a riqueza, abrangência e multidimensionalidade que a literatura teórica hoje reconhece no conceito de desenvolvimento. A concretização deste objetivo requer que medidas mais tradicionais de desenvolvimento como o rendimento per capita sejam complementadas com outros indicadores de espectro mais alargado.

Contudo, a generalidade desses indicadores, propostos sobretudo nas últimas duas décadas, não captam todas as dimensões relevantes do fenómeno em estudo. Nesse sentido, subsiste o desafio para a emergência de índices de desenvolvimento suscetíveis de captar, de forma inovadora e abrangente, as diversas vertentes integrantes desse conceito. A relevância de uma correta medição de um fenómeno decisivo como o desenvolvimento impõe um caráter prioritário a este desafio. 


\section{Referências}

ADELMAN, I. (1999). 'The Role of Government in Economic Development”. Working Paper, n. ${ }^{\circ}$ 890, University of California.

AMARO, R. (2003) 'Desenvolvimento: Um Conceito Ultrapassado ou em Renovação? "Da Teoria à Prática e da Prática à Teoria”. Cadernos de Estudos Africanos, 4.

AMIN, S. (1976). Unequal Development: An Essay on the Social Formations of Peripheral Capitalism. New York: Monthly Review Press.

BAUER, P.; YAMEY, B. (1957). The Economics of Under-developed Countries. Cambridge University Press.

BHAGWATI, J. (1982). “Directly Unproductive Profit-Seeking Activities”. Journal of Political Economy, vol. 90(5); p. 988-1002.

BONENTE, B.; FILHO, N. (2008). “Há uma Nova Economia do Desenvolvimento?”. Revista de Economia, 34(1); p. 77-100.

BOOYSEN-WOLTHERS, A. (2007). The Development Status of Women in South Africa: Patterns, Progress and Profiles. University of the Free State.

BRITO, B. (2004). Turismo Ecológico: uma Via para o Desenvolvimento Sustentável em São Tomé e Príncipe. Instituto Universitário de Lisboa (ISCTE-IUL).

CARDOSO, F. (1973). “Associated-Dependent Development: Theoretical and Practical Implications”. STEPAN, A. [ed.] Authoritarian Brazil. New Haven, CT: Yale University Press.

CARDOSO, F.; FALETTO, E. (1979). Dependency and Development in Latin America, Berkeley: University of California Press.

CHANG, H.-J. (2003). "Rethinking Development Economics: An Introduction”. Rethinking Development Economics, 1-18, London: Anthem Press.

CLARK, D. (2007). “Abstract Concepts of Development”. Visions of Development: A Study of Human Values, 9-26, Cheltenham: Edward Elgar.

DAG HAMMARSKJOLD FOUNDATION (1982). What Now? Another Development. The 1975 Dag Hammarsköld Report on Development and International Cooperation, Sweden: Motala Gafiska.

DAVIS, T. (2009) “What Is Sustainable Development?”. URL [on-line]: <http:// www.enviropedia.com>.

DOS SANTOS, T. (1970). “The Structure of Dependence”. American Economic Review, vol. 60(2); p. 231-36.

ESTEVÃO, J. (1999). “O Estado e o Desenvolvimento Económico”. Elementos para uma Orientação de Leitura. Universidade Técnica de Lisboa (ISEG).

FINE, B. (2003). "Neither the Washington Nor the Post-Washington Consensus: An Introduction". FINE, J. et al. [eds]. Development Policy in the Twenty First Century: Beyond the Post-Washington Consensus, London: Routledge.

FORTUNATO, A. (2000). Lições de Economia do Crescimento e Desenvolvimento. Coimbra: Faculdade de Economia da Universidade de Coimbra (FEUC).

FRANK, A. (1967). Capitalism and Underdevelopment in Latin America. New York: Monthly Review Press. 
FRIEDMANN, J. (1992). Empowerment: the Politics of Alternative Development. Cambridge: Blackwell.

FURTADO, C. (1973). "Underdevelopment and Dependence: the Fundamental Connections”. Working Paper, 17. Center of Latin American Studies, University of Cambridge.

GHAI D. (1990). Participatory Development: Some Perspectives from Gross-Roots Experiences. London: Macmillan Press.

GOULET, D. (1992) "Development: Creator and Destroyer of Values". World Development, 20(3); p. 467-75.

GRAAFF, J.; VENTER, D. (2001). "Understanding the World Systems”. COETZEE, J.; GRAAFF, F.; WOODS, G. [eds.]. Development Theory, Policy and Practice. Cape Town: Oxford University Press.

HARRIS, J. (2001). A Survey of Sustainable Development: Social and Economic Dimensions. Washington: Island Press.

HARRIS, J.; TODARO, M. (1970). "Migration, Unemployment and Development: A Two-Sector Analysis”. American Economic Review, 61(1); p. 126-42.

HAYAMI, Y.; GODO, Y. (2005). Development Economics: From the Poverty to the Wealth of Nations, New York: Oxford University Press.

HIRSCHMAN, A. (1958). The Strategy of Economic Development. New Haven, Conn.: Yale University Press.

HOUEÉ, P. (2001). Le Développement Local au Défi de la Mondialisation. Paris: L'Harmattan.

HUNT, D. (1989). Economic Theories of Development: An Analysis of Competing Paradigms, New York: Harvester Wheatsheaf.

KORTEN, D. (1992). "People-Centered Development: Alternative for a World in Crisis". BAUZON, K. [ed.]. Development and Democratization in the Third World: Myths, Hopes and Realities. New York: Crane Russak.

KRUEGER, A. (1990). “Government Failures in Development”. Journal of Economic Perspectives, 4(3); p. 9-23.

KRUEGER, A. (1974). “The Political Economy of the Rent-Seeking Society”. American Economic Review, 64(3); p. 291-303.

KRUGMAN, P. (1994). “The Fall and Rise of Development Economics”. RODWIN, L.; SCHON, D. S. [eds.] Rethinking the Development Experience: Essays Provoked by the Work of Albert O. Hirschman. Washington, D.C.: Brookings Institution.

LEWIS, A. (1955). The Theory of Economic Growth, London: Allen e Unwin.

LEWIS, A. (1954). "Economic Development with Unlimited Supplies of Labour". Manchester School of Economic and Social Studies, 22(2); p. 139-91.

MARTINUSSEN, J. (1997). Society, State \& Market: A Guide to Competing Theories of Development. London e New York: Zed Books Ltd.

McKINNON, R. (1973). Money and Capital in Economic Development. Washington, D.C.: Brookings Institution.

MEADOWS, D. (1972). The Limits of Growth. London: Pan Books. 
MYRDAL, G. (1957). Economic Theory and Underdeveloped. London: Duckworth.

NURKSE, R. (1953). Problems of Capital Formation in Underdeveloped Countries. New York: Oxford University Press.

NURKSE, R. (1952). "Some International Aspects of the Problem of Economic Development”. American Economic Review, XLII(2); p. 571-83.

OMAN, C.; WIGNARAJA, G. (1991). The Postwar Evolution of Development Thinking. New York: St Martin's Press.

PECQUEUR, B. (1989). Le Développement Local. Paris: Syros-Alternatives.

PERROUX, F. (1955). "Note on the Concept of Growth Poles". Economie Appliquée, vol. 8; p. 307-20.

PREBISCH, R. (1949). "The Economic Development of Latin America and its Principal Problems”. Economic Bulletin for Latin America, vol. 7(1); p. 1-22.

RANIS, G.; FEI, J. (1961). “A Theory of Economic. Development”. American Economic Review, vol. 51(4); p. 533-65.

REIS, V. (2005). Desenvolvimento e Investimento Directo Estrangeiro em Cabo Verde: Contributo Português. Instituto Universitário de Lisboa (ISCTE-IUL).

ROSENTEIN-RODAN, P. (1943). "Problems of Industrialization of Eastern and South-Eastern Europe”. Economic Journal, vol. 53(210/211); p. 202-11.

ROSTOW, W. (1960). “The Stages of Economic Growth: A Non-Communist Manifesto". Cambridge University Press.

ROSTOW, W. (1956). "The Take-Off Into Self-Sustained Growth”. Economic Journal, vol. 66(261); p. 25-48.

SACHS, I. (1986). Ecodesenvolvimento: Crescer Sem Destruir. São Paulo: Vértice.

SACHS, I. (1980). Stratégies de l'Écodeveloppement. Paris: Les Éditions Ouvrières.

SEERS, D. (1979). “Os Indicadores de Desenvolvimento: O Que Estamos a Tentar Medir?” Análise Social, XV(6o); p. 949-68.

SEN, A. (1999). Development as Freedom. New York: Alfred A. Knopf.

SHAPIRO, H.; TAYLOR, L. (1990). "The State and Industrial Strategy". World Development, 18(6); p. 861-878.

SHAW, E. (1973). Financial Deepening in Economic Development. New York: Oxford University Press.

SILVA, M. (1963). "Fases de um Processo de Desenvolvimento Comunitário". Análise Social, I(4); p. 538-58.

SILVA, M. (1962). Desenvolvimento Comunitário: Uma Técnica de Progresso Social. Lisboa: Associação Industrial Portuguesa (AIP).

SINGER, H. (1950). "The Distribution of Gains Between Investing and Borrowing Countries". American Economic Review, 40(2); p. 473-85.

SUNKEL, O. (1973). “Transnational Capitalism and National Disintegration in Latin America”. Social and Economic Studies, 22(1); p. 156-71.

TAYLOR, L. (1993). "Stabilisation, Adjustment and Reform”. The Rocky Road to Reform. Cambridge Mass.: The MIT Press. 
TODARO, M.; SMITH, S. (2000). Economic Development. New York: Oxford University Press.

UNDP (2003). Human Development Report. New York: Oxford University Press. UNDP (1998). Human Development Report. New York: Oxford University Press.

UNDP (1996). Human Development Report. New York: Oxford University Press.

UNDP (1994). Human Development Report. New York: Oxford University Press.

UNDP (1990). Human Development Report. New York: Oxford University Press.

VACHON, B. (1993), Le Développement Local: Théorie et Pratique, Montréal: Gaëtem Morin.

WALLERSTEIN, I. (1980), The Modern World-System II: Mercantilism and the Consolidation of the European World-Economy, 1600-1750. New York: Academic Press.

WALLERSTEIN, I. (1979). The Capitalist World-Economy. Cambridge University Press.

WALLESTEIN, I. (1974). The Modern World-System, Capitalist Agriculture and the Origins of the European World-Economy in the Sixteenth Century. New York: Academic Press.

WCED (1987). Our Common Future: Brundtland Report, New York: Oxford University Press.

WILliamSON, J. (2004). The Washington Consensus as Policy Prescription for Development.Washington D.C.: Institute for International Economics.

WILLIAMSON, J. (1990). "What Washington Means by Policy Reform”. Latin American Adjustment: How Much Has Happened?. Washington, D.C.: Institute of International Economics.

WORLD BANK (1997). World Development Report 1997: The State in a Changing World. New York: Oxford University Press.

WORLD BANK (1993). The East Asian Miracle: Economic Growth and Public Policy. New York: Oxford University Press.

WORLD BANK (1991). World Development Report 1991: The Challenge of Development. New York: Oxford University Press.

Recebido em: 28 de outubro de 2011

Aceito em: o8 de outubro de 2012 
